\title{
Plasma Cortisol and Progesterone Responses to Low Doses of Adrenocorticotropic Hormone in Ovariectmized Lactating Cows
}

\author{
Chikako YOSHIDA ${ }^{1)}$ and Toshihiko NAKAO $^{2)}$ \\ ${ }^{1)}$ Department of Animal Science, Graduate School for International Development and \\ Cooperation (IDEC), Hiroshima University and ${ }^{2}$ Laboratory of Theriogenology, Department \\ of Veterinary Medicine, Faculty of Agriculture, Yamaguchi University, 1677-1 Yoshida, \\ Yamaguchi 753-8515, Japan \\ \#Present: Field Center for Sustainable Agriculture and Forestry, Faculty of Agriculture, Niigata \\ University, Japan
}

\begin{abstract}
The objective of this study was to describe the responses of the plasma progesterone and cortisol concentrations in ovariectomized lactating cows to low doses of adrenocorticotropic hormone $(\mathrm{ACTH})$. The estrous cycles in 3 lactating cows were synchronized, and the cows were ovariectomized in the luteal phase. ACTH challenge tests were conducted at doses of 3, 6, 12 and $25 \mathrm{IU}$. Blood samples were collected at $30 \mathrm{~min}$ intervals, and the plasma progesterone and cortisol concentrations were analyzed by EIA. A concomitant rise in plasma progesterone and plasma cortisol was observed in cows treated with 12 IU or higher doses of ACTH. Significant increments in the plasma cortisol concentrations were observed at all doses of ACTH. The means $( \pm S E)$ of the peak plasma progesterone concentrations after the 3, 6, 12 and 25 IU ACTH challenge tests were $0.6 \pm 0.1,1.3 \pm 0.4,1.5 \pm 0.3$ and 2.4 $\pm 0.3 \mathrm{ng} / \mathrm{ml}$, respectively. The means of the peak plasma cortisol concentrations in the 3 cows after the ACTH challenge were $14.0 \pm 1.5,17.0 \pm 2.5,23.3 \pm 3.0$, and $33.3 \pm 7.0 \mathrm{ng} / \mathrm{ml}$, respectively. The effects of the doses, time after treatment, and their interaction on the plasma progesterone concentrations after the ACTH challenge were significant $(\mathrm{P}<0.01)$. Likewise, the effects of the doses, time after treatment, and their interaction on the plasma cortisol concentrations after the ACTH challenge were significant $(\mathrm{P}<0.01)$. The mean AUC values for the plasma progesterone and cortisol concentrations after the ACTH treatments were also significantly affected by the dose of ACTH $(\mathrm{P}<0.01$ and $\mathrm{P}<0.05$, respectively). A significantly positive correlation was obtained between the peak plasma progesterone and cortisol concentrations after different doses of ACTH $(r=0.7, \mathrm{P}<0.05)$. The results suggest that lactating dairy cows are capable of secreting a significant amount of adrenal progesterone, reaching up to the minimal concentration necessary to cause suppression of estrus in response to 12 IU ACTH $(\mathrm{P}<0.01)$. The concomitant plasma cortisol concentration was $23.3 \mathrm{ng} / \mathrm{ml}$.

Key words: Adrenal cortex, Progesterone, Cortisol, Adrenocorticotropic hormone (ACTH), Dairy cows
\end{abstract}

(J. Reprod. Dev. 52: 797-803, 2006)

$\mathbf{A}^{\mathrm{n}}$ high heat detection rate is a primary requirement for effective reproductive management of dairy herds [1, 2]. Recently, the

Accepted for publication: August 18, 2006

Published online: September 21, 2006

Correspondence: T. Nakao (e-mail: tnakao@yamaguchi-u.ac.jp) duration of estrus in lactating cows has been reported to be substantially shortened [3-6], and the percentage of cows exhibiting standing estrus has been decreased [6-9].

Some studies have indicated that cows or heifers with weakened estrous signs show suprabasal 
progesterone levels in their milk fat or plasma [1012]. The suprabasal plasma progesterone concentrations during the follicular phase and the estrous period could originate either from incomplete luteolysis or extragonadal sources such as the pituitary-adrenal axis [11,13-16]. Generally, a plasma progesterone concentration of $1.0 \mathrm{ng} / \mathrm{ml}$ is considered the threshold level for biological activity [17].

Previous studies have reported that cattle respond with high concentrations of plasma progesterone and cortisol after an ACTH challenge $[14,15,18,19]$. These reports showed that more than 48 IU of ACTH was required to cause an increase in the plasma progesterone concentration up to $1.1-1.4 \mathrm{ng} / \mathrm{ml}$ in heifers. It has been suggested that heifers under some kinds of stress have weakened estrous signs. These kinds of stress possibly cause release of an amount of ACTH sufficient to stimulate secretion of progesterone from the adrenal cortex $(1.0 \mathrm{ng} / \mathrm{ml}$ or higher in plasma).

Our recent study showed that a 25 IU ACTH challenge in ovariectomized lactating dairy cows resulted in a rise in plasma progesterone levels up to $2.0-3.7 \mathrm{ng} / \mathrm{ml}$ and a concomitant rise in plasma cortisol up to $33.2-46.5 \mathrm{ng} / \mathrm{ml}$, respectively [20]. We presume that even lower doses of ACTH cause a rise in the plasma progesterone concentrations up to the minimal concentrations necessary to cause suppression of estrus.

The objective of this study was, therefore, to describe the responses in the plasma progesterone and cortisol concentrations to 3 to 25 IU of ACTH in ovariectmized lactating cows.

\section{Materials and Methods}

\section{Animals and housing}

This experiment was carried out at the Hiroshima University Experimental Farm, HigashiHiroshima, Hiroshima Prefecture, in the southwestern region of Japan during the period from the 13th of June 2003 to the 10th of August 2003. Three Holstein Friesian lactating cows in their 4th-6th lactations that were beyond the breeding period and due to be culled for replacement because of old age and poor milk production were used for this study. Their days in milk were 346 to 496 and their daily milk yields ranged from 11.2 to $17.6 \mathrm{~kg}$. Prior to the experiment, they showed normal estrous cycles. The cows were kept in a free-stall barn with their herd mates during the experiment, except during the ACTH challenge tests when they were kept in another separate stall and tied up with 3-4 meter long ropes. They were milked twice daily. All handling of the animals was performed with a minimal disruption of their daily routine and with minimal stress. The experimental protocols and animal care during the experiment met the International Guiding Principles for Biomedical Research Involving Animals (Council for International Organizations of Medical Sciences).

\section{Schedule of treatment and blood sampling}

The animals were ovariectomized and used for the ACTH challenge tests to examine the response of adrenal progesterone to ACTH. Prior to ovariectomy, cows with normal estrous cycles were treated intramuscularly with $25 \mathrm{mg}$ of $\mathrm{PGF}_{2} \alpha$ (dinoprost tromethamine, Pronalgon $\mathrm{F}^{\circledR}$, Pfizer, Tokyo, Japan) twice at an interval of 14 days to synchronize estrus. The cows were pretreated with $100 \mu \mathrm{g}$ GnRH analog, fertirelin acetate $\left(\right.$ Conceral $^{\circledR}$, Takeda Schering-Plough. Co. Ltd., Tokyo, Japan), 7 days before each $\mathrm{PGF}_{2} \alpha$ administration. Ovariectomy was conducted for all 3 cows through an incision in the vaginal wall 10 days after the second $\mathrm{PGF}_{2} \alpha$ treatment.

Four consecutive ACTH challenge tests at an interval of 7 days were carried out from 5 days after the ovariectomy. Indwelling jugular vein catheters were applied $6 \mathrm{~h}$ prior to each ACTH challenge. Four different doses of ACTH (tetracosactide acetate, Cortrosyn ${ }^{\circledR}$, Daiichi Pharmaceutical Co., Tokyo, Japan), 3, 6, 12 and 25 IU, were administered intramuscularly to each cow at $0000 \mathrm{~h}$ of each experimental day at an interval of 7 days.

Blood samples were collected at 0930-1000 h daily by tail venepuncture throughout the estrous cycle until the cows were ovariectomized. Blood was sampled twice daily for 2 days from the 3 rd day after $\mathrm{PGF}_{2} \alpha$ treatment. For $24 \mathrm{~h}$ after ovariectomy, blood was sampled every $4 \mathrm{~h}$, and then it was sampled daily for 5 days until the day of the first ACTH challenge test. Daily blood samples were also collected during the 7 day period between each ACTH challenge test. Blood samples were collected through indwelling jugular vein catheters every $30 \mathrm{~min}$ for $12 \mathrm{~h}$ to complete the 
ACTH challenge test. Blood samples were immediately stored at $4 \mathrm{C}$ and centrifuged $(1,700 \times$ $g$ for $15 \mathrm{~min}$ ) within $30 \mathrm{~min}$ after collection. Plasma was stored at $-20 \mathrm{C}$ until analysis for cortisol and progesterone.

\section{Hormone assay}

Plasma cortisol concentrations were determined by an enzyme immunoassay established and validated by the authors [20]. Cortisol antiserum (anti cortisol-3-CMO-BSA IgG, Cosmo Bio, Tokyo, Japan) diluted with assay buffer 40,000 times and horseradish peroxidase (HRP)-cortisol conjugate (cortisol-3-CMO-HRP, Cosmo Bio) solution $(1: 100,000)$ were used. The intra- and interassay coefficients of variation in the high and low cortisol pooled plasma samples were $7.2 \%$ and $23.4 \%(n=6)$ and $3.0 \%$ and $3.2 \%(n=5)$, respectively.

Plasma concentrations of progesterone were measured according to the method described by Isobe and Nakao [21]. The antiserum used was raised in rabbits against progesterone-3(E)carboxymethyl oxime-BSA (Kambegawa Institute, Tokyo, Japan). Horseradish peroxidase (HRP)labeled progesterone (Sigma Aldrich) was used as the tracer. The intra- and interassay coefficients of variation in the high and low progesterone pooled plasma samples were 3.7 and $4.4 \%(n=5)$ and 2.2 and $1.4 \%(n=5)$, respectively.

The response of the plasma concentrations of cortisol and progesterone after ACTH administration was shown by the values before the ACTH challenge, the peak value after ACTH, and the amount of cortisol and progesterone secreted after ACTH. The basal concentrations of both hormones were shown by the lowest value among the values of the two samples collected at $0.5 \mathrm{~h}$ and within 1 min before ACTH administration.

Area under curve (AUC) values of plasma cortisol and progesterone after the ACTH challenge until the concentrations ceased to be baseline were calculated. Correlation between the AUCs of plasma progesterone and cortisol after the ACTH challenge was examined.

\section{Statistical analysis}

The results are presented as the mean \pm standard error (SE).

The effect of the ACTH doses, time before and after $\mathrm{ACTH}$, and interaction between dose and time on the progesterone and cortisol concentrations were analyzed by multivariate analysis of variance (Excel Statistics Ver. 4, Esumi Co., Tokyo, Japan).

The basal plasma progesterone and cortisol concentrations before ACTH treatment were considered to be the lower concentrations at $-0.5 \mathrm{~h}$ or $0.0 \mathrm{~h}$ of ACTH injection. The significance of differences in plasma concentrations of progesterone and cortisol between pre-treatment and each different time after ACTH administrations were analyzed by Student's t-test.

An adjusted AUC (response area) was determined as the total area between the actual progesterone and cortisol response and the baseline up to where the consecutive value returned to baseline. The effects of doses of ACTH on AUCs were analyzed by two-way analysis of variance (Excel Statistics Ver. 4).

The significance of correlation between two variables was tested using Pearson's correlation coefficients.

A probability of $\mathrm{P}<0.05$ was considered statistically significant.

\section{Results}

Estrus was synchronized in the 3 cows after the 1st and 2nd $\mathrm{PGF}_{2} \alpha$ treatments. All 3 animals showed standing estrus after the 1 st $\mathrm{PGF}_{2} \alpha$ treatment, whereas the cows expressed only secondary estrous signs after the 2 nd $\mathrm{PGF}_{2} \alpha$ treatment. All 3 cows had corpus luteum when they were subjected to ovariectomy. Plasma progesterone concentrations declined after the 1st $\mathrm{PGF}_{2} \alpha$ treatment in the 3 animals and rose to 2.0 $\mathrm{ng} / \mathrm{ml}$ or higher after the $2 \mathrm{nd} \mathrm{PGF}_{2} \alpha$ treatment.

Cortisol concentrations in the plasma remained below $10 \mathrm{ng} / \mathrm{ml}$ during most of the estrous cycle until ovariectomy.

The means \pm SE of the peak plasma progesterone concentrations after the 3, 6, 12 and 25 IU ACTH challenge tests were $0.6 \pm 0.1,1.3 \pm 0.4,1.5 \pm 0.3$ and $2.4 \pm 0.3 \mathrm{ng} / \mathrm{ml}$, respectively. The means of the peak plasma cortisol concentrations in the 3 cows after the ACTH challenge tests were $14.0 \pm 1.5,17.0$ $\pm 2.5,23.3 \pm 3.0$ and $33.3 \pm 7.0 \mathrm{ng} / \mathrm{ml}$, respectively. The peak plasma progesterone concentrations were observed 0.5 or $1.0 \mathrm{~h}$ after ACTH treatment.

The effects of doses, time after treatment, and their interaction on the plasma progesterone concentrations after ACTH challenge were 

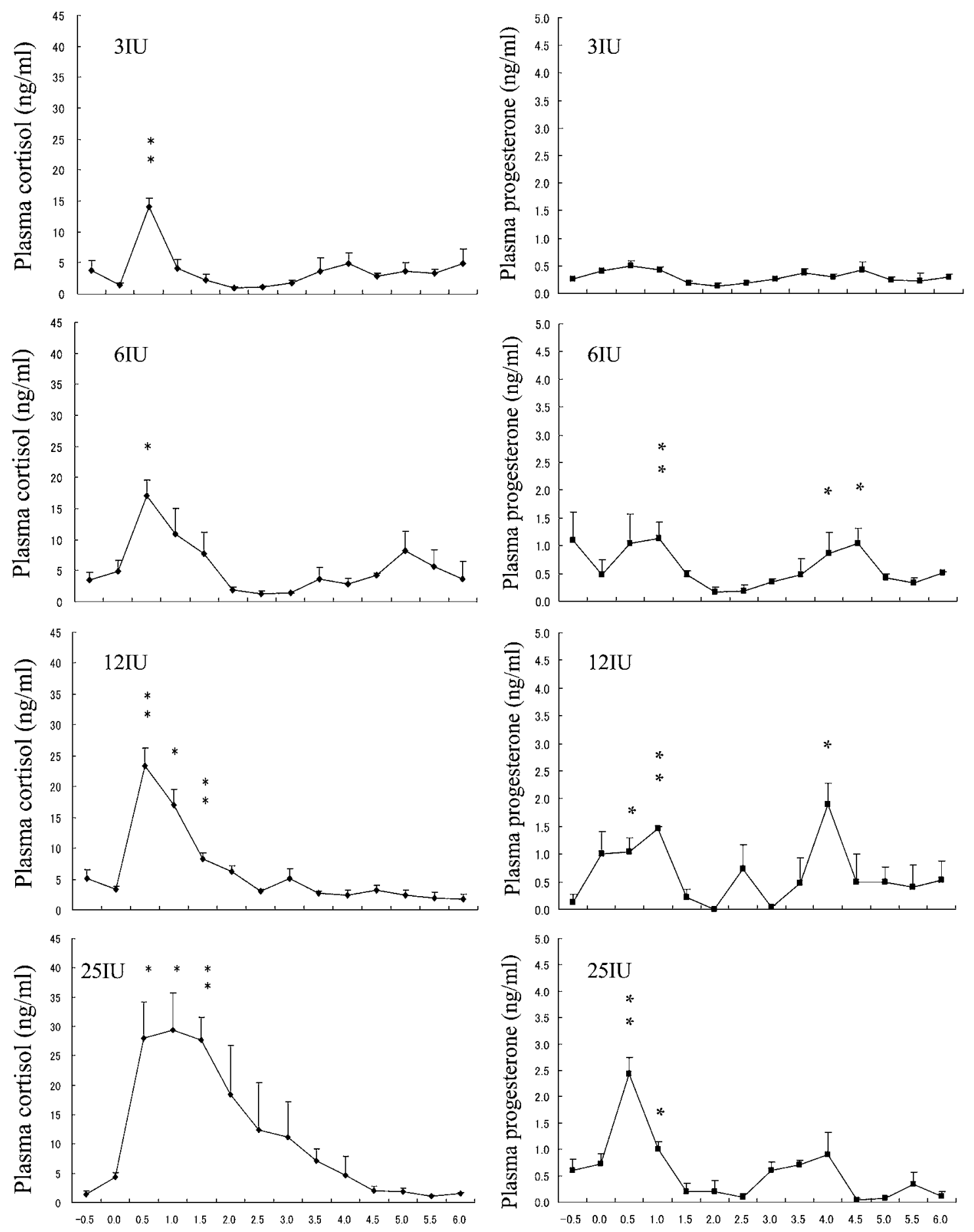

Time after ACTH treatment (h)

Fig. 1. Plasma progesterone and cortisol response in ovariectomized lactating cows after intramuscular administration of $3,6,12$ and 25 IU ACTH. Mean $\pm S E(n=3) .{ }^{*}(P<0.05),{ }^{* *}(P<0.01)$ : significantly higher than the baseline. 
Table 1. Area under the curve for the plasma progesterone and cortisol concentrations in cows after challenge with different doses of ACTH $(n=3$, mean \pm SE).

\begin{tabular}{|c|c|c|c|c|}
\hline \multirow[b]{2}{*}{ Item } & \multicolumn{4}{|c|}{ ACTH } \\
\hline & $3 \mathrm{IU}$ & $6 \mathrm{IU}$ & $12 \mathrm{IU}$ & $25 \mathrm{IU}$ \\
\hline \multicolumn{5}{|l|}{ Plasma progesterone } \\
\hline Time to reach peak $(\mathrm{h})$ & 0.7 & 0.8 & 0.8 & 0.5 \\
\hline Area under the curve & $0.2 \pm 0.1^{\mathrm{a}}$ & $0.6 \pm 0.1^{\mathrm{a}}$ & $1.5 \pm 0.3^{b}$ & $1.9 \pm 0.3^{\mathrm{b}}$ \\
\hline \multicolumn{5}{|l|}{ Plasma cortisol } \\
\hline Time to reach peak $(\mathrm{h})$ & 0.5 & 0.5 & 0.5 & 0.7 \\
\hline Area under the curve & $8.2 \pm 1.8^{c}$ & $12.6 \pm 4.0^{c}$ & $22.5 \pm 0.6^{\mathrm{d}}$ & $64.1 \pm 21.4^{\mathrm{d}}$ \\
\hline
\end{tabular}

Both the AUCs for the plasma progesterone and cortisol concentrations were significantly affected by the dose of ACTH $(\mathrm{P}<0.01$ and $\mathrm{P}<0.05$, respectively).

Means with different superscripts significantly differ $(a / b: P<0.01, c / d: P<0.05)$.

significant $(\mathrm{P}<0.01)$. Likewise, the effects of doses, time after treatment, and their interaction on the plasma cortisol concentrations after ACTH challenge were significant $(\mathrm{P}<0.01)$. The mean AUC values for the plasma progesterone and cortisol concentrations after the ACTH treatments were also significantly affected by the dose of ACTH $(\mathrm{P}<0.01$ and $\mathrm{P}<0.05$, respectively).

Figure 1 shows the response of the plasma cortisol and progesterone concentrations in the 3 cows after challenge at different doses of ACTH ranging from $3 \mathrm{IU}$ to $25 \mathrm{IU}$. No significant response was observed for plasma progesterone after administration of 3 IU ACTH. However, a concomitant rise in plasma progesterone was observed along with plasma cortisol in the cows injected with 6 IU or higher doses of ACTH. The plasma progesterone concentrations significantly increased from the basal value at $0.5,1.0$ and $4.0 \mathrm{~h}$ after the $12 \mathrm{IU}$ ACTH injection $(\mathrm{P}<0.05, \mathrm{P}<0.01$ and $\mathrm{P}<0.05$, respectively) and at 0.5 and $1.0 \mathrm{~h}$ after the 25 IU ACTH $(\mathrm{P}<0.01$ and $\mathrm{P}<0.05$, respectively). Compared with the plasma progesterone concentrations in the cows administered 3 IU ACTH, the cows treated with 12 IU ACTH showed significantly higher plasma progesterone at $1.0 \mathrm{~h}$ and $4.0 \mathrm{~h}$ after treatment $(\mathrm{P}<0.01$ and $\mathrm{P}<0.05$, respectively). Similarly, the plasma progesterone concentrations of the cows after the $25 \mathrm{IU}$ ACTH challenge were significantly higher at $0.5 \mathrm{~h}$ and 1.0 $\mathrm{h}$ after treatment $(\mathrm{P}<0.05)$.

A transitory increase in plasma progesterone, which was not observed in the cortisol response, was observed at around $3.5 \mathrm{~h}$ after the ACTH challenge tests.

The AUCs for the plasma progesterone and

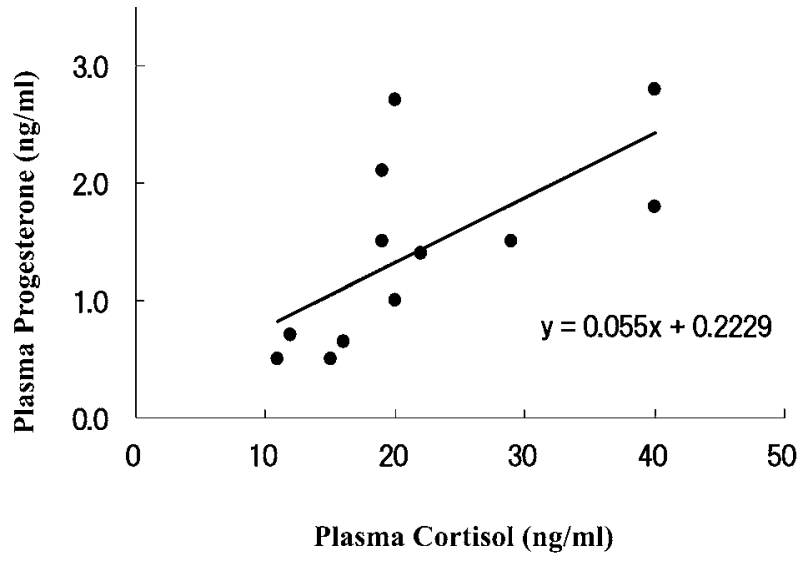

Fig. 2. Correlation between the peak plasma progesterone and cortisol concentrations after challenge with 3,6 , 12 and $25 \mathrm{IU}$ ACTH in 3 lactating cows $(\mathrm{n}=3, \mathrm{r}=0.7$, $\mathrm{P}<0.05)$.

cortisol concentrations after ACTH injections at different doses are shown in Table 1. The mean AUC values for the plasma progesterone and cortisol concentrations after ACTH treatment were significantly affected by the dose of ACTH $(\mathrm{P}<0.01$ and $\mathrm{P}<0.05$, respectively).

A significantly positive correlation was obtained between the peak plasma progesterone and cortisol concentrations after different doses of ACTH ( $r=$ 0.7, $\mathrm{P}<0.05$ ) (Fig.2).

\section{Discussion}

In the present study, the 3 ovariectomized cows responded with an increase in their plasma progesterone and cortisol concentrations after 
ACTH treatment. The effects of the ACTH doses, time after treatment, and interaction between dose and treatment on both the plasma progesterone and cortisol concentrations were significant $(\mathrm{P}<0.01)$. A significant rise in the plasma progesterone concentrations was observed after administrations of $6 \mathrm{IU}$ or higher doses of ACTH. However, the plasma progesterone concentrations before ACTH administration were relatively high in the $6 \mathrm{IU}$ treated group. Therefore, the effect of 6 IU doses of ACTH in ovariectmized cows should be confirmed through further study. After the $12 \mathrm{IU}$ ACTH treatment, the peak plasma progesterone concentrations were observed after $1.0 \mathrm{~h}$ and reached up to $1.5 \mathrm{ng} / \mathrm{ml}$, which was significantly different from that after 3 IU of ACTH. The concomitant peak plasma cortisol concentration was $23.3 \mathrm{ng} / \mathrm{ml}$ after the $12 \mathrm{IU}$ ACTH treatment.

Alam et al. [22] reported a significant rise in plasma progesterone up to $1.48 \mathrm{ng} / \mathrm{ml}(\mathrm{P}<0.01)$ and plasma cortisol up to $23.3 \mathrm{ng} / \mathrm{ml}$ in multiparous non-lactating cows after $1.0 \mathrm{mg}$ (100 IU) of ACTH. Wagner et al. [19] reported that a challenge with 100 IU ACTH in 5 normal cyclic Holstein heifers resulted in a significant increase in their plasma progesterone concentrations $(\mathrm{P}<0.001)$ up to $1.0-1.5$ $\mathrm{ng} / \mathrm{ml}$ after the ACTH treatment. In the same study, ovariectmized heifers responded with a rise in their plasma progesterone concentrations up to $1.18 \mathrm{ng} / \mathrm{ml}$ after treatment with $100 \mathrm{IU}$ ACTH [19]. More recently, Bage et al. [14] reported that 5 ovariectomized virgin heifers showed an increase in their plasma progesterone concentrations up to $3.5 \mathrm{nmol} / 1(1.1 \mathrm{ng} / \mathrm{ml})$ after intramuscular administration of $48 \mathrm{IU}$ ACTH. Thus, heifers, nonlactating cows, and lactating cows have been shown to be capable of secreting a significant amount of progesterone, resulting in plasma progesterone concentrations of up to $1.0 \mathrm{ng} / \mathrm{ml}$ or higher. The doses of ACTH that caused a significant increase in plasma progesterone concentrations, reaching up to $1.0 \mathrm{ng} / \mathrm{ml}$ or above, were higher in previous studies using non-lactating cows or heifers than the doses used in the present study, which employed lactating cows. It has yet to be discovered whether this is due to a difference in the responsiveness of the adrenal cortex between lactating and non-lactating cattle.

We assume that any stress causing a rise in plasma cortisol up to $23.3 \mathrm{ng} / \mathrm{ml}$ or above results in a significant rise in plasma progesterone, which may adversely affect estrous expression.

A number of stressors cause enhancement of the pituitary-adrenal axis and secretion of cortisol, including heat stress $[16,23,24]$, milk yields [25, 26], palpation per rectum [27], confinement [28] and lameness [29]. Further studies are needed to discover whether the stressors mentioned above can cause a significant rise in plasma progesterone concentrations.

In conclusion, lactating dairy cows are capable of secreting a significant amount of adrenal progesterone, reaching up to the minimal concentration necessary to cause suppression of estrus in response to $12 \mathrm{IU}$ ACTH $(\mathrm{P}<0.01)$. The peak response of the plasma cortisol concentrations to $12 \mathrm{IU}$ ACTH was $23.3 \mathrm{ng} / \mathrm{ml}$.

\section{Acknowledgements}

The authors extend their sincere thanks to the Hiroshima University Experimental Farm for the use of their animals and facilities. Donation of $\mathrm{PGF}_{2} \alpha$ by Pfizer (Tokyo) and GnRH analog by Takeda Schering-Plough Animal Health (Tokyo) are acknowledged with grateful thanks.

\section{References}

1. Gröhn YT, Rajala-Schultz PJ. Epidemiology of reproductive performance in dairy cows. Anim Reprod Sci 2000; 60-61: 605-614.

2. Roche JF, Mackey D, Diskin MD. Reproductive management of postpartum cows. Anim Reprod Sci 2000; 60-61: 703-712.

3. Dransfield MBG, Nebel RL, Pearson RE, Warnick LD. Timing of insemination for dairy cows identified in estrus by a radiotelemetric estrus detection system. J Dairy Sci 1998; 81: 1874-1882.

4. Xu ZZ, McKnight DJ, Vishwanath R, Pitt CJ, Burton LJ. Estrus detection using radiotelemetory or visual observation and tail painting for dairy cows on pasture. J Dairy Sci 1998; 81: 2890-2896.

5. At-Taras EE, Spahr SL. Detection and characterization of estrus in dairy cattle with an electronic heat mount detector and an electronic activity tag. J Dairy Sci 2001; 84: 792-798. 
6. Yoshida C, Nakao T. Some characteristics of primary and secondary oestrous signs in highproducing dairy cows. Reprod Dom Anim 2005; 40: 150-155.

7. Kerbrat S, Disenhaus C. A proportions for an updated behavioral characterization of the oestrus period in dairy cows. Appl Anim Behav Sci 2004; 87: 223-238.

8. Stevenson JS, Schmidt MK, Call EP. Estrous intensity and conception rates in Holsteins. J Dairy Sci 1983; 66: 275-280.

9. Van Vliet JH, Van Eerdenburg FJCM. Sexual activities and oestrus detection in lactating Holstein cows. Appl Anim Behav Sci 1996; 50: 57-69.

10. Schopper D, Schemer R, Weiler U, Claus R. Influence of milk yield on the fertility of dairy cows post partum: evaluation of progesterone profiles. Reprod Dom Anim 1993; 28: 225-235.

11. Duchens M, Maciel M, Gustafsson H, Forsberg M, Rodríguez-Martínez H, Edqvist L-E. Influence of perioestrous suprabasal progesterone levels on cycle length, oestrous behavior and ovulation in heifers. Anim Reprod Sci 1995; 37: 95-108.

12. Båge $\mathbf{R}$, Gustafsson $\mathbf{H}$, Forsberg $\mathbf{M}$, Larsson $\mathbf{B}$, Rodríguez-Martínez $\mathbf{H}$. Suprabasal progesterone levels in repeat breeder heifers during the pro-and oestrous period. Theriogenology 1997; 47: 141.

13. Hein KG, Allrich RD. Influence of exogenious adrenocorticotropic hormone on estrous behavior in cattle. J Anim Sci 1992; 70: 243-247.

14. Båge R, Forsberg M, Gustafsson $\mathbf{H}$, Larsson B. Effect of ACTH-challenge on progesterone and cortisol levels in ovariectomised repeat breeder heifers. Anim Reprod Sci 2000; 63: 65-76.

15. Stoebel DP, Moberg GP. Effect of adrenocorticotropin and cortisol on luteinizing hormone surge and estrous behavior of cows. J Dairy Sci 1982; 65: 1016-1024.

16. Thatcher WW. Effect of Season, climate, and temperature on reproduction and lactation. J Dairy Sci 1974; 57: 361-368.

17. Pineda MH. Female Reproductive System: Ovarian Hormones. In: Pineda MH (ed.), McDonald's Veterinary Endocrinology and Reproduction Fifth Edition. Blackwell Publishing Company; 2003: 324333.

18. Gwazdauskas FC, Thatcher WW, Wilcox CJ.
Adrenocorticotropin alteration of bovine peripheral plasma concentrations of cortisol, corticosterone, and progesterone. J Dairy Sci 1972; 55: 1165-1169.

19. Wagner WC, Strohbehn RE, Harris PA. ACTH, corticoids and luteal function in heifers. J Anim Sci 1972; 35: 789-793.

20. Yoshida C, Nakao T. Response of plasma cortisol and progesterone after ACTH challenge in ovariectmized lactating dairy cows. J Reprod Dev 2005; 51: 99-107.

21. Isobe $\mathbf{N}, \mathbf{N a k a o} \mathbf{T}$. Direct enzyme immunoassay of progesterone in bovine plasma. Anim Sci J 2003; 74: 369-373.

22. Alam MGS, Dobson H, Fitzpatrick RJ. Endocrine response to different doses of ACTH in cows. $\mathrm{Br} \mathrm{Vet}$ J 1986; 142: 239-245.

23. Alvarez MB, Johnson HD. Environmental heat exposure on cattle plasma catecholamine and glucocorticoids. J Dairy Sci 1973; 56: 189.

24. Abilay TA, Johnson HD, Madan M. Influence of environmental heat on peripheral plasma progesterone and cortisol during the bovine estrous cycle. J Dairy Sci 1975; 58: 1836-1840.

25. Miyazawa K. Changes in the plasma cortisol and glucose level after applying stimulus into the jugular vein to collect blood, stimulus on the teat and the stimulus of milking in cows. Res Bull Obihiro Univ 1984; 13: 229-235.

26. Blum JW, Jans F, Moses W, Fröhli D, Zemp M, Wanner M, Hart IC, Thun R, Keller U. Twentyfour-hour pattern on blood hormone and metabolite concentrations in high-yielding dairy cows: effects of feeding low or high amounts of starch, or crystalline fat. Zbl Vet Med A 1985; 32: 401-418.

27. Nakao T, Sato T, Moriyoshi M, Kawata K. Plasma cortisol response in dairy cows to vagioscopy, genital palpation per rectum, and artificial insemination. J Vet Med A 1994; 41: 16-21.

28. Stoebel DP, Moberg GP. Repeated acute stress during the follicular phase and luteinizing hormone surge of dairy heifers. J Dairy Sci 1982; 65: 92-96.

29. Endo H, Ogata Y, Takahashi K, Fujikura T, Konno M. Management for claw diseases in free-stall type dairy farms using evaluation data on pain stress and metabolic profile test. J Livestock Med 2003; 50: 241248 (In Japanese with English summary). 